\title{
Energetic underpinnings of yellow dung fly mating success in the field
}

\author{
Wolf U. Blanckenhorn ${ }^{1}$ \\ 1 Department of Evolutionary Biology \& Environmental Studies, University of Zurich, Winterthurerstrasse 190, CH-8057, Zurich, Switzerland \\ http://zoobank.org/187306AE-D01D-4F76-B61C-A0C3F35ED6CB \\ Corresponding author: Wolf U. Blanckenhorn (Wolf.Blanckenhorn@ieu.uzh.ch)
}

Academic editor: Philippe Jeanneret • Received 1 May 2021 • Accepted 1 July 2021 • Published 22 July 2021

\begin{abstract}
Foraging provides the basis for animal reproduction, but requires energy and time to be sustained, entailing a trade-off. Whereas females should maximize their time foraging for resources, males should minimize their foraging time by optimizing time budgets to maximize their access to mating partners.

Mark-resight field studies are difficult and hence uncommon for small insects. Yellow dung flies (Scathophaga stercoraria L.) abound on pastures in cold-temperate regions across the northern hemisphere. Adult flies lick nectar from flowers for energy, but require small insect prey to produce eggs and sperm. Males wait for females around fresh cow dung, but at one point also need to replenish their energy and/or sperm reserves in the surrounding vegetation. Their foraging time budgets should depend on their body size, nutritional energy reserves, availability of sperm, competitor and female density.

Marked male dung flies whose nutritional status was experimentally manipulated - water only (null control); water + sugar (energy replenishment); or water, sugar + Drosophila prey (energy and sperm replenishment) - were repeatedly observed on an experimental pasture for an entire day. Both nutrient types were expected to increase the mating success of especially large males. The total number of resighted males seen copulating was lowest for water-treated flies. Mating success was positively related to body size. The distance travelled between dung pats was greater for males fed sugar or prey and also increased with body size, while pat residence times decreased with size. No differences were found between the sugar- and prey-fed groups. Crucially however, there was no evidence in the field for a time budget or mating advantage of small males when nutrients were limited.
\end{abstract}

\section{Key Words}

body size, energy reserves, field observations, food manipulation, foraging, mating success, Scathophaga stercoraria, reproduction

\section{Introduction}

Foraging provides the basis for animal life histories (Stephens and Krebs 1986), as all necessary energy first needs to be collected before it can subsequently be allocated to the various life history or fitness components such as growth, survival, and reproduction (Roff 1992; Stearns 1992). Moreover, foraging itself requires energy and time to be sustained. In this sense foraging is an unusual, merely intermediating life history component. Nevertheless, foraging and mating are mutually exclusive activities in terms of time or energy (Blanckenhorn et al. 1995; Zera and Harshman 2001), and males and females are not expected to resolve this trade-off in similar ways. Sexual selection theory predicts that females should maximize their time foraging because their offspring production depends directly on the quality and quantity of resources gathered (Darwin 1971; Trivers 1972). Males, in contrast, should instead minimize their time spent foraging as long as they can energetically sustain their activities, because their fitness is a direct function of their access to female mating partners (Bateman 1948). Within species, smaller individuals (of both sexes) require less food in absolute terms to maintain their activity (Ghiselin 1974; Reiss 1989; Blanckenhorn et al. 1995, 2007; Reim et al. 2006a, b). Small males can therefore increase their mating effort at the expense of foraging effort (called the small-male time budget advantage: cf. Blanckenhorn et 
al. 1995; Blanckenhorn and Viele 1999). This may partly compensate their other usual competitive disadvantages, as large males are usually more successful in acquiring mates (Andersson 1994; Clutton-Brock 1988) and also tend to be stronger and more efficient at subduing prey or extracting nutrients (Blanckenhorn and Viele 1999; Blanckenhorn 2000, 2005). Therefore, male and female time and energy budgets are expected to differ substantially for any species (Stephens and Krebs 1986).

To understand the mating system of any particular species, time and energy allocation of both sexes to various activities must be investigated (Shuker and Simmons 2014). This first and foremost concerns the expected trade-off between foraging and reproduction (defined above). While assessment of field behaviour is relatively straightforward for vertebrates (Clutton-Brock 1988; Andersson 1994), individualized observations are difficult if not impossible for small insects (e.g. Fincke 1982; Blanckenhorn and Perner 1996). Yellow dung flies (Scathophaga stercoraria L.; Diptera: Scathophagidae) approach the size of honey bees (ca. 7-13 mm long) and are common on livestock (especially cattle) pastures in cold-temperate regions of the northern hemisphere (Blanckenhorn et al. 2010; Simmons et al. 2020). Adult flies lick nectar from flowers for energy but additionally require small insect prey to produce eggs and sperm (anautogeny: Foster 1967; Gibbons 1980; Blanckenhorn et al. 2007, 2010; Kaufmann et al. 2013). Therefore, females spend most of their time foraging for prey and nectar in the forest or the vegetation surrounding a pasture, and only come to the dung when ready to lay eggs (Parker 1970, 1978). Males, in contrast, mainly are found waiting for females on pastures around freshly deposited (cow) dung, although territorial defence of this resource necessitated by females as oviposition substrate is often precluded by the sheer number of competitors present (Borgia 1981, 1982; Jann et al. 2000). In this mating system of resource defence polygyny with at times severe scramble as well as contest competition (Parker 1978; Shuker and Simmons 2014), males attempt to copulate with incoming females without any courtship, and subsequently guard and defend their females against other males during oviposition (Parker 1978; Simmons et al. 2020). Struggles for possession of a female may harm all individuals involved, particularly the smaller females and males. After oviposition into the dung, in which the coprophagous (dung-eating) larvae develop and feed, the female leaves the pat to forage and replenish her eggs, whereas males tend to wait or switch pats to secure more females. Males only rarely forage on or around the dung pat even though they could (Gibbons 1980). However, at one point also males need to replenish energy and/or sperm, and thus leave to forage in the vegetation. This mating system requires males to make repeated decisions about whether to stay or leave a particular dung pat in search of females vs. temporarily abandoning reproduction altogether to feed elsewhere (Parker 1978; Simmons et al. 2020). These decisions should depend on their body size, nutritional energy reserves, availability of sperm, as well as the competitor (male) and female density.

I here report the results of replicated field observations of individual yellow dung fly males using the classic mark-resight approach, with male nutritional status additionally being experimentally manipulated. Numerous males of various ages and sizes were randomly collected on a given (random) day in the season (cf. Jann et al. 2000), weighed, marked and subsequently supplied in the laboratory for 24-48 h with three different nutrient regimes, before being released again on their pasture to be observed for an entire day. The nutritional treatments were: 1) water only; 2) water + sugar (in lieu of nectar); and 3) water, sugar + Drosophila prey. Although the current nutritional status and age of the captured field males was unknown, I had the following expectations/predictions. Relative to the water only treatment (= null control), I expected the water + sugar treatment to replenish energy (for flight and fight), while the water + sugar + prey treatment additionally would replenish male sperm stores (for mating; Blanckenhorn and Henseler 2005). The extra nutrients were expected to disproportionally help large males because of their greater absolute energy and sperm demand (Ward and Simmons 1991; Reim et al. 2006a, b, 2009; Blanckenhorn et al. 2007; Kaufmann et al. 2013). Ultimately, I expected both nutrient supplements, but especially the treatment including prey, to increase the mating success of all, but especially the large males, as they generally enjoy competitive mating advantages (Jann et al. 2000; Blanckenhorn et al. 2003). Because small males require less energy to begin with to sustain their activity, I expected the general size advantage of large males in acquiring mates to diminish, or even reverse, under energy-limited conditions (water treatment).

\section{Materials and methods}

\section{Field procedures}

We conducted at total of six field markings (days), three during the spring and three during the fall fly season (Jann et al. 2000), spread over two years, always working on our experimental farm in Fehraltdorf near Zürich, Switzerland $\left(47^{\circ} 23^{\prime} \mathrm{N}, 8^{\circ} 44^{\prime} \mathrm{E}\right)$. Each field marking started with randomly catching ca. 100 male yellow dung flies of various sizes and ages currently active on the pasture. These flies were subsequently grouped into 3.5 litre plastic containers $\left(2.2 \times 1.2 \times 1.2 \mathrm{dm}^{3}\right)$ supplied with water only. Back in the laboratory, all flies were first weighed with a Mettler balance, and subsequently marked with numbered, coloured opalith discs on their thorax (described below). Males were then randomly allocated to one of three of the above containers in groups of 30 numbered individuals. Containers were supplied with one of three nutrient treatments: water, water + sugar, or water + sugar + Drosophila prey. The containers with the nour- 
ished flies were kept overnight in a climate chamber in the laboratory at ca. $20^{\circ} \mathrm{C}$ for at least $24 \mathrm{~h}$ (but up to $48 \mathrm{~h}$ depending on outside weather conditions). In the morning of the experimental day, containers were transported back to our pasture in Fehraltorf for the marked flies to be released and observed for the entire day.

On each observation day, from early morning to late evening, up to 5 people (students of our annual ecology course) regularly screened the entire pasture for individually identifiable marked male flies, particularly all freshly appearing dung pats, which were marked with coloured, numbered flags. Returning to the same dung pat in haphazard, more or less regular intervals, observers noted fly identity (coloured number) and observation time as well as the pairing status of any marked fly seen. From these raw data, I later extracted the following variables ultimately analysed for all marked individuals resighted at least once on the pasture: 1) pairing status (paired or not) as an estimate of mating success; 2) the estimated distance from the previous to the next dung pat occupied, in case an individual switched pats (in m), as an indicator of flight endurance; 3 ) the number of times a given individual was observed during a given day (anywhere it was seen); 4) the total number of different pats visited by an individual (i.e. pat switches) as an indicator of searching activity, with distances between the pats estimated and averaged (cf. 2 above); 5) the daytime a fly was first and last seen on the pasture as an indicator of total activity time during the experimental day.

\section{Preliminary marking experiment}

Flies were individually marked with numbered (1-99) opalith discs (6 available colours) that were dorsally glued with shellac onto the flies' thorax. Disks and shellac glue are commercially available for marking honey bees from Bienen-Meier (Künten, Switzerland; Burkhard 1999). We only marked males because for the smaller females these disks are too large or heavy, and also because disks are not visible for females in copula.

Prior to our field experiment, two tests of our marking technique were conducted in April and May 1998, during which 276 and 447 (respectively) marked but otherwise untreated males of various sizes were released on two different pastures near Fehraltorf during the course of Burkhards (1999) thesis project. The results of these preliminary experiments are here briefly reported to validate our results.

Three days after marking, ca. $15 \%$ of all originally marked flies were resighted on the pasture; two days later this number dropped to $3 \%$, and after 10 days no marked individuals remained to be seen. Neighbouring pastures were also searched. Thus, not least because of many other cow pastures in the vicinity, marked flies disappeared quite fast from the focal pasture. As usual in such assessments, emigration and death could not be distinguished.

\section{Statistical analyses}

The variables defined above were computed and all data aggregated per individual male as the independent statistical unit. All variables were subjected to separate analyses of variance with food treatment as fixed factor (3 levels), initial body weight as continuous covariate (first also including the interaction, which was removed if not significant at $\mathrm{P}>0.15$ ), and sampling date as random effect. The number of flies resighted (of all originally marked) were analysed with binomial errors, the total number of copulations per individual were analysed with Poisson errors, and all other variables were $\log _{10}$-transformed as necessary to meet statistical assumptions to be analysed with normal errors.

\section{Results}

Of roughly 540 males originally marked and released (6 dates $\times 3$ treatments $\times 30$ flies/treatment), 231 were resighted (ca. 43\%). Of these, 46 were resighted only once (on one dung pat), and 114 occupied only one dung pat for longer time, such that the total sample of resighted males having switched pats at least once was $\mathrm{N}=117$ (Table 1). Resighting rate was relatively high compared to Burkhards (1999) preliminary experiments reported above because observations started within one hour after fly release on the pasture in the morning.

The body mass of the flies did not vary significantly among our three treatments, nor did the total number of daily sightings or the total observation time, as of course should not be the case given random assignment to feeding treatments (Table 1). All variables varied strongly among the six experimental days (random effect; Table 1), mainly due to seasonal weather conditions.

The proportion of males resighted tended to be lower for the water treatment (Table 1), as these males were expected to be in utmost energy demand. The proportion of water-treated flies seen copulating was also lower (Table 1: 0.22 vs. 0.35 vs. 0.40 ), although this effect was not quite significant due to the low number of observed copulations in our entire sample. We saw a total of 89 copulations: two males were found copulating 4 times, two males 3 times, 8 males 2 times, and 59 males once (Fig. 1a). Independent of nutritional treatment, copulation success was overall positively related to male body size (Table 1; Fig. 1a). The distance travelled to the next pat increased with body size (Fig. 1c), and there was a trend of larger males visiting more pats (Fig. 1b; Table 1), both indicating greater energy reserves of larger individuals. In contrast, pat residence times decreased with body size, again suggesting greater activity of larger males (except for the males fed with sugar and prey; Fig. 1d). Nutritional treatment only influenced the distance travelled to the next pat, which was greater for sugar- and prey-fed males than 
Table 1. Mean \pm SE and statistical significance of all behavioural variables assessed for three nutritional treatments $(N$ refers to total males seen, and males seen on more than one pat). Data for the six observation dates are absolute counts.

\begin{tabular}{|c|c|c|c|c|c|c|c|c|c|c|}
\hline & \multirow{2}{*}{\multicolumn{2}{|c|}{$\begin{array}{c}\text { water } \\
(N=60,26)\end{array}$}} & \multirow{2}{*}{\multicolumn{2}{|c|}{$\begin{array}{l}\text { water, sugar } \\
(N=93,54)\end{array}$}} & \multirow{2}{*}{\multicolumn{2}{|c|}{$\begin{array}{c}\text { water, sugar, prey } \\
(\mathrm{N}=78,37)\end{array}$}} & \multirow{2}{*}{\multicolumn{4}{|c|}{$\chi^{2} / \mathbf{F}^{*}$}} \\
\hline & & & & & & & & & & \\
\hline & mean & SE & mean & SE & mean & SE & treat & size & date & txs \\
\hline No. of flies (of 30 ) resighted & 10 & \pm 1.81 & 15.5 & \pm 2.86 & 13 & \pm 2.21 & 3.18 & - & - & - \\
\hline 18 May 1999 & 11 & & 24 & & 8 & & & & & \\
\hline 5 June 1999 & 14 & & 14 & & 14 & & & & & \\
\hline 15 June 1999 & 8 & & 14 & & 13 & & & & & \\
\hline 18 October 2004 & 17 & & 24 & & 21 & & & & & \\
\hline 27 October 2004 & 6 & & 8 & & 6 & & & & & \\
\hline 4 November 2004 & 4 & & 9 & & 11 & & & & & \\
\hline Pr. copulated & 0.22 & \pm 0.06 & 0.35 & \pm 0.06 & 0.40 & \pm 0.09 & 1.98 & 20.0 & 25.1 & - \\
\hline Initial body mass (mg) & 25.43 & \pm 1.16 & 25.87 & \pm 0.87 & 26.49 & \pm 1.06 & 0.45 & - & 18.8 & - \\
\hline Total time active (min) & 129.1 & \pm 18.1 & 182.3 & \pm 17.6 & 146.9 & \pm 17.0 & 1.17 & 0.09 & 2.21 & - \\
\hline Times observed & 4.28 & \pm 0.47 & 6.55 & \pm 0.60 & 5.40 & \pm 0.61 & 2.88 & 0.27 & 5.62 & - \\
\hline No. of pats visited & 2.00 & \pm 0.22 & 2.23 & \pm 0.15 & 2.00 & \pm 0.15 & 1.68 & 2.75 & 3.23 & - \\
\hline Distance to next pat $(\mathrm{m})$ & 16.41 & \pm 2.78 & 28.19 & \pm 2.43 & 23.90 & \pm 2.68 & 5.24 & 6.34 & 1.93 & - \\
\hline Min. pat residence time ( $\mathrm{min})$ & 33.23 & \pm 5.96 & 38.70 & \pm 4.36 & 36.17 & \pm 3.45 & 1.14 & 7.59 & 1.66 & 2.18 \\
\hline
\end{tabular}

* bold: $\mathrm{P}<0.05$; bold italic: $\mathrm{P}<0.1$
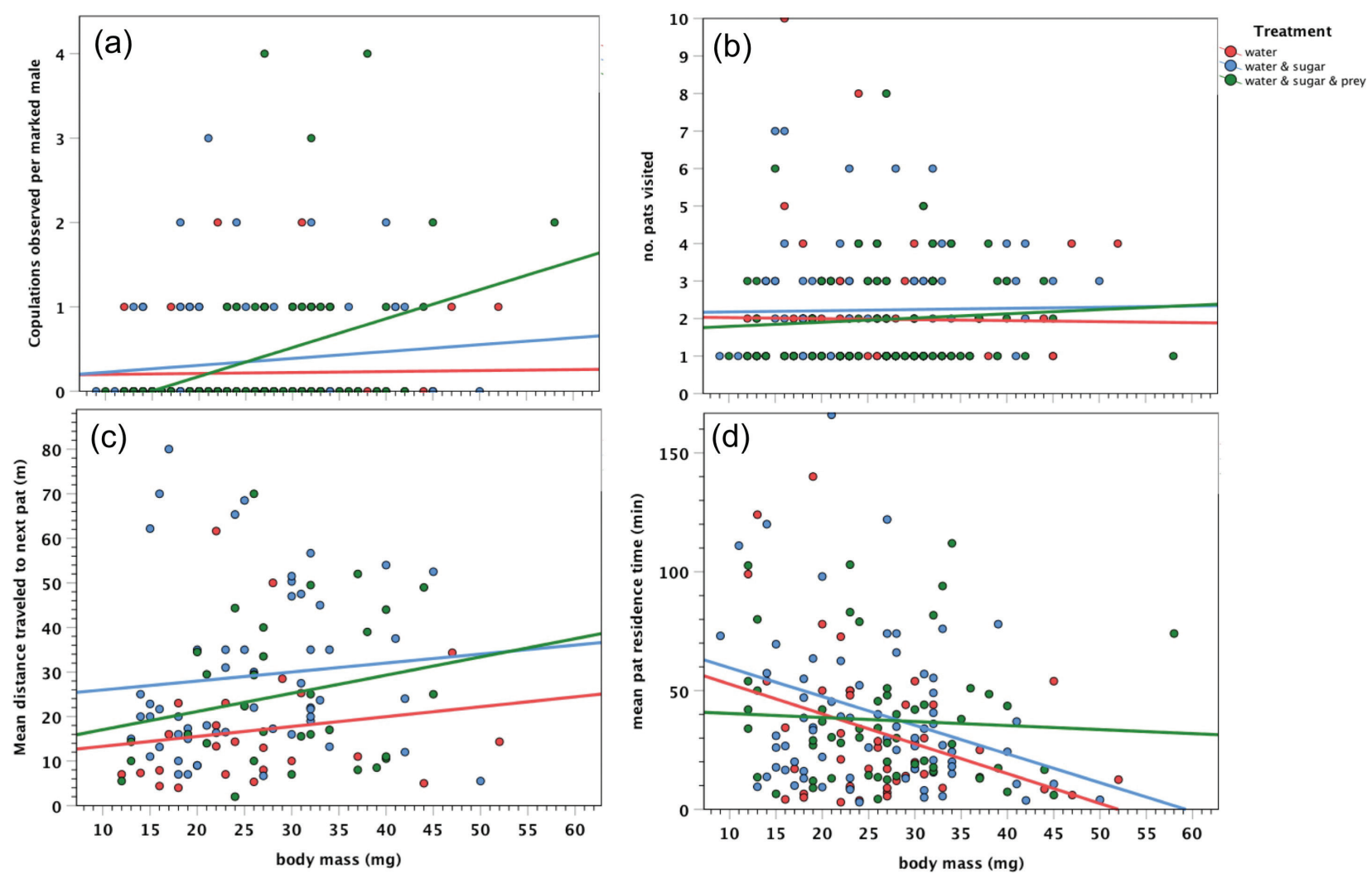

Figure 1. (a) Total number of copulations observed, (b) no. of pats visited, (c) distance to next pat visited, and (d) pat residence times of males as a function of their body mass and food treatment.

for water-fed males (Table 1; Fig. 1c). The body mass by treatment interaction was never significant $(\mathrm{P}>0.1$; Table 1), contrary to expectations.

\section{Discussion}

Reproductive success of an organism is a function of intrinsic (e.g. body size) as well as extrinsic, environmental factors (e.g. mate or food availability, weather conditions, etc.). Although foraging success is often far removed from fitness (Stephens and Krebs 1986), it ultimately provides all energy to be invested in reproduction (e.g. Blanckenhorn 1991; Lemon 1991). I here manipulated the feeding status of yellow dung fly males caught and marked on a pasture, expecting that this would influence their subsequent time budgets, mate search behaviour and ultimate mating success. While such mark-resight studies combined with food manipulations are common in vertebrates (e.g. Clutton-Brock 1988; Andersson 1994), they 
are tricky and thus rarely performed with small insects. In general, larger and flightless insects are more suited for such studies (e.g. dragonflies, butterflies or water striders: Fincke 1982; Elgar and Pierce 1988; Blanckenhorn and Perner 1996).

Adult yellow dung flies feed on nectar for energy but additionally prey on other insects, and the nutrients derived from these different foraging modes serve different purposes. Sugars are required for fuelling flight, and proteins from prey are used to produce the eggs or sperm needed for reproduction, although sugars can likely be derived also from prey (Foster 1967; Gibbons 1980; Blanckenhorn et al. 2007, 2010; Kaufmann et al. 2013). I therefore employed three feeding treatments: water only, water plus sugar, and water plus sugar plus Drosophila prey.

Although not quite statistically significant, the total number of resighted individuals and the proportion of males seen copulating following release on their native pasture after food treatment was lowest for the flies only given water. This indicates that these flies were energetically limited and needed to first feed before becoming reproductively active again (Table 1 ). Although the total number of copulations observed (89) was low, copulation success was positively related to male body size, as is typical in this species (Fig. 1; Jann et al. 2000; Kraushaar and Blanckenhorn 2002; Blanckenhorn et al. 2003). As expected in response to their extra energy supply, the distance travelled by males when switching dung pats was greater for males fed sugar or prey, and also increased with body size (Table 1; Fig. 1). Further, pat residence times decreased with body size (except for males fed with sugar and prey, possibly relating to their greater copulation success), again signifying energetic advantages for large males. Crucially however, there were few differences between the sugar- and prey-fed groups, contrary to expectations, especially not for their copulation rates (Table 1). The adult age of our test males caught on the pasture remained unestimated here, which would have required assessment of wing injuries (so-called age-grading, usually requiring wing removal for digitizing: Burkhard et al. 2002). In addition to body size, fly age likely influences the behavioural variables assessed here, although no correlation between body size and age can be safely assumed in our data set (Blanckenhorn et al. 2001; Burkhard et al. 2002).

While yellow dung flies cannot convert sugars into proteins (contrary to some other insects; Foster 1967; Tauber et al. 1986; Blanckenhorn et al. 2007), it seems that they can derive sugars for flight also from prey, as flies can be kept in the laboratory with prey only (i.e. without sugar; personal observation). Thus our two food treatments overlapped, potentially explaining lack of differences. As both male and female flies can store sperm for extended periods of time in their testes and spermathecae (respectively), apparently many of the sugar-fed males still had sufficient sperm for mating when caught to begin with. Sperm are initially produced upon adult male emergence given prey is available, a physiological process requir- ing 3-7 days (Blanckenhorn and Henseler 2005). Sperm production may thereafter continue throughout their adult life, so the males must forage prey once their sperm reserves are depleted (which suffice for ca. 4-5 copulations: Ward and Simmons 1991).

Some of our behavioural traits showed expected time budget differences between feeding groups (Table 1). The initial body mass of flies, and the total time they were observed were not meant to differ among feeding groups because flies were randomly allocated. By contrast, more available energy for flight and fight would predict more pat switches, lower patch residence times, and/or farther distances covered by males fed with sugar and/or prey, which was indeed found and should have contributed to the observed higher mating success of these well-fed males (Fig. 1). Well-fed males would also likely engage in more fights with other males when trying to take over females, and especially large males are able to fly away with their female in case of such attacks (Parker 1978; Blanckenhorn et al. 2008; Simmons et al. 2020). Importantly, however, I did not find any evidence in the field for the small-male time budget advantage (Blanckenhorn et al. 1995; Blanckenhorn and Viele 1999; Blanckenhorn et al. 2008), which would have been indicated by greater mating chances of smaller males in the energy-limited, water-only group, but there were no significant body mass by treatment interactions whatsoever.

Our six observation days were distributed evenly across typical spring and fall fly seasons (Parker 1970; Gibbons 1987; Jann et al. 2000; Blanckenhorn et al. 2001). Even within seasons fly densities and body sizes change markedly, as there are at least four overlapping generations per year in Switzerland (Jann et al. 2000). Together with unpredictable weather conditions, seasonality best explains the rather variable resighting rates found here for this heat-sensitive fly during our six experimental days (Table 1). This rather erratic random effect likely contributed to the lack of significance and low effective sample sizes for our key variables.

In conclusion, our study shows that even for small insects, mark-recapture studies can be effective for gaining behavioural insights into reproductive success in the field. Ironically, Switzerland is not the best place for such studies because of the high density of cow pastures, rendering the tracking of small marked flies in confined geographic space difficult.

\section{Acknowledgements}

I thank multiple ecology students whose names are long forgotten for performing the field experiments and observations, but especially Dieter Burkhard for conducting invaluable preliminary markings. This work was funded over the years by the Zoological Museum of the University of Zurich and continuous grants from the Swiss National Science Foundations to Wolf Blanckenhorn (last 3100A0-111775). In memory of Paul I. Ward, who died too early. 


\section{References}

Andersson M (1994) Sexual Selection. Princeton Univ. Press, Princeton.

Bateman AJ (1948) Intra-sexual selection in Drosophila. Heredity, 2, 349-368. https://doi.org/10.1038/hdy.1948.21

Blanckenhorn WU (1991) Fitness consequences of foraging success in water striders (Gerris remigis; Heteroptera: Gerridae). Behavioral Ecology 2: 46-55. https://doi.org/10.1093/beheco/2.1.46

Blanckenhorn WU (1998) Adaptive phenotypic plasticity in growth, development, and body size in the yellow dung fly. Evolution 52: 1394-1407. https://doi.org/10.1111/j.1558-5646.1998.tb02021.x

Blanckenhorn WU (2000) The evolution of body size: What keeps organisms small? Quarterly Review of Biology 75: 385-407. https:// doi.org/10.1086/393620

Blanckenhorn WU (2005) Behavioral causes and consequences of sexual size dimorphism. Ethology 111: 977-1016. https://doi. org/10.1111/j.1439-0310.2005.01147.x

Blanckenhorn WU, Preziosi RF, Fairbairn DJ (1995) Time and energy constraints and the evolution of sexual size dimorphism - to eat or to mate? Evolutionary Ecology 9: 369-381. https://doi.org/10.1007/ BF01237760

Blanckenhorn WU, Perner D (1996) Life history dependent behavioural variation in water striders Aquarius remigis. Ethology 102: 9931007. https://doi.org/10.1111/j.1439-0310.1996.tb01177.x

Blanckenhorn WU, Viele SNT (1999) Foraging in yellow dung flies: testing for a small-male time budget advantage. Ecological Entomology 24: 1-6. https://doi.org/10.1046/j.1365-2311.1999.00171.x

Blanckenhorn WU, Henseler C, Burkhard DU, Briegel H (2001) Summer decline in populations of the yellow dung fly: diapause or quiescence? Physiological Entomology 26: 260-265. https://doi. org/10.1046/j.0307-6962.2001.00245.x

Blanckenhorn WU, Kraushaar U, Reim C (2003) Sexual selection on morphological and physiological traits and fluctuating asymmetry in the yellow dung fly. Journal of Evolutionary Biology 16: 903-913. https://doi.org/10.1046/j.1420-9101.2003.00587.x

Blanckenhorn WU, Henseler C (2005) Temperature-dependent ovariole and testis maturation in the yellow dung fly. Entomologia Experimentalis et Applicata 116: 159-165. https://doi.org/10.1111/j.15707458.2005.00316.x

Blanckenhorn WU, Fanti J, Reim C (2007) Size-dependent energy reserves, energy utilization and longevity in the yellow dung fly. Physiological Entomology 32: 372-381. https://doi.org/10.1111/j.13653032.2007.00589.x

Blanckenhorn WU, Birrer M, Meier C, ReimC, Teuschl Y, Weibel D (2008) Size-dependent mating success at various nutritional states in the yellow dung fly. Ethology 114: 752-759. https://doi.org/10.1111/ j.1439-0310.2008.01521.x

Blanckenhorn WU, Pemberton AJ, Bussière LF, Roembke J, Floate KD (2010) Natural history and laboratory culture of the yellow dung fly, Scathophaga stercoraria (L.; Diptera: Scathophagidae). Journal of Insect Science 10: 1-17. https://doi.org/10.1673/031.010.1101

Borgia G (1981) Mate selection in the fly Scatophaga stercoraria: female choice in a male-controlled system. Animal Behaviour 29: 71-80. https://doi.org/10.1016/S0003-3472(81)80153-4

Borgia G (1982) Experimental changes in resource structure and male density: size-related differences in mating success among male Scathophaga stercoraria. Evolution 36: 307-315. https://doi. org/10.1111/j.1558-5646.1982.tb05046.x
Burkhard DU (1999) Is adult longevity size-dependent in the yellow dung fly, Scathophaga stercoraria (L.) (Diptera: Scathophagidae)? Diploma thesis, University of Zürich.

Burkhard DU, Ward PI, Blanckenhorn WU (2002) Using age grading by wing injuries to estimate size-dependent adult survivorship in the field: a case study of the yellow dung fly Scathophaga stercoraria. Ecological Entomology 27: 514-520. https://doi.org/10.1046/ j.1365-2311.2002.00453.x

Clutton-Brock TH [Ed.] (1988) Reproductive success. University of Chicago Press, Chicago.

Darwin C (1871) The Descent of Man, and Selection in Relation to Sex. John Murray, London. https://www.biodiversitylibrary.org/ page/20211933

Elgar MA, Pierce NE (1988) Mating success and fecundity in an ant-tended lycaenid butterfly. In: Clutton-Brock TH (Ed.) Reproductive success. University of Chicago Press, Chicago, 59-75.

Fincke OM (1982) Lifetime mating success in a natural population of the Damselfly Enallagma hageni. Behavioural Ecology and Sociobiology 10: 293-302. https://doi.org/10.1007/BF00302820

Foster W (1967) Hormone-mediated nutritional control of sexual behavior in male dung flies. Science 158: 1596-1597. https://doi. org/10.1126/science.158.3808.1596

Ghiselin MT (1974) The Economy of Nature and the Evolution of Sex. University of California Press, Berkely.

Gibbons DS (1980) Prey consumption, mating and egg production in Scathophaga stercoraria (Dipt., Scathophagidae) in the laboratory. Entomol Month Mag 116: 25-32.

Gibbons DS (1987) The causes of seasonal changes in numbers of the yellow dung fly Scathophaga stercoraria. Ecological Entomology 12: 173-185. https://doi.org/10.1111/j.1365-2311.1987.tb00996.x

Jann P, Blanckenhorn WU, Ward PI (2000) Temporal and microspatial variation in the intensities of natural and sexual selection in the yellow dung fly Scathophaga stercoraria. Journal of Evolutionary Biology 13: 927-938. https://doi.org/10.1046/j.1420-9101.2000.00230.x Kaufmann C, Reim C, Blanckenhorn WU (2013) Size-dependent insect flight energetics at different sugar supplies. Biological Journal of the Linnean Society 108: 565-578. https://doi.org/10.1111/j.10958312.2012.02042.x

Kraushaar U, Blanckenhorn WU (2002) Population variation in sexual selection and its effect on size allometry in two dung fly species with contrasting sexual size dimorphism. Evolution 56: 307-321. https:// doi.org/10.1111/j.0014-3820.2002.tb01341.x

Lemon WC (1991) Fitness consequences of foraging behaviour in the zebra finch. Nature 352: 153-155. https://doi.org/10.1038/352153a0

Parker GA (1970) The reproductive behaviour and the nature of sexual selection in Scathophaga stercoraria L. (Diptera: Scathophagidae) I. Diurnal and seasonal changes in population density around the site of mating and oviposition.Journal of Animal Ecology 39: 185-204. https://doi.org/10.2307/2895

Parker GA (1978) Searching for mates In: Krebs JR, Davies NB (Eds) Behavioural ecology (1 ${ }^{\text {st }}$ Edn.). Blackwell, Oxford, 214-244.

Reim C, Teuschl Y, Blanckenhorn WU (2006) Size-dependent effects of larval and adult food availability on reproductive energy allocation in the yellow dung fly. Functional Ecology 20: 1012-1021. https:// doi.org/10.1111/j.1365-2435.2006.01173.x

Reim C, Teuschl Y, Blanckenhorn WU (2006) Size-dependent effects of temperature and food stress on energy reserves and starvation resistance in yellow dung flies. Evolutionary Ecology Research 8: 1215-1234. 
Reim C, Kaufmann C, Blanckenhorn WU (2009) Size-dependent energetics of metamorphosis in the yellow dung fly, Scathophaga stercoraria. Evolutionary Ecology Research 11: 1111-1130.

Reiss MJ (1989) The Allometry of Growth and Reproduction. Cambridge University Press, Cambridge. https://doi.org/10.1017/ CBO9780511608483

Roff DA(1992) The Evolution of Life Histories. Chapmann Hall, New York.

Shuker DM, Simmons LW (2014) The Evolution of Insect Matins Systems. Oxford University Press, Oxford. https://doi.org/10.1093/acprof:oso/9780199678020.001.0001

Simmons LW, Parker GA, Hosken DJ (2020) Evolutionary insight from a humble fly: sperm competition and the yellow dung fly. Philosophical Transactions of the Royal Society B, 375: e20200062. https:// doi.org/10.1098/rstb.2020.0062

Stearns SC (1992) The Evolution of life Histories. Oxford University Press, Oxford.

Stephens DW, Krebs JR (1986) Foraging Theory. Princeton University Press, Princeton, New Jersey.

Tauber MJ, Tauber CA, Masaki S (1986) Seasonal Adaptations of Insects. Oxford University Press, Oxford.

Trivers RL (1972) Parental investment and sexual selection. In: Campbell B (Ed.) Sexual selection and the descent of man. Chicago, A1dine, 136-179. https://doi.org/10.4324/9781315129266-7

Ward PI, Simmons LW (1991) Copula duration and testes size in the yellow dung fly, Scathophaga stercoraria (L.): the effects of diet, body size, and mating history. Behav Ecol Sociobiol 29: 77-85. https://doi.org/10.1007/BF00166481
Zera AJ, Harshman LG (2001) The physiology of life history trade-offs in animals. Annual Review of Ecology and Systematics: 95-126. https://doi.org/10.1146/annurev.ecolsys.32.081501.114006

\section{Supplementary material 1}

\section{Data File in Excel for Supplemental publication}

Author: Wolf U. Blanckenhorn

Data type: Excel text file

Explanation note: Sheet1 contains the complete data file for the analyses performed in this paper. Variable names are self-explanatory. Sheet 2 contains some extra but incomplete (hence excluded) data from one day in 2005 because the weather did not allow completion.

Copyright notice: This dataset is made available under the Open Database License (http://opendatacommons.org/licenses/odbl/1.0/). The Open Database License $(\mathrm{ODbL})$ is a license agreement intended to allow users to freely share, modify, and use this Dataset while maintaining this same freedom for others, provided that the original source and author(s) are credited.

Link: https://doi.org/10.3897/alpento.5.68153.supp11 